\title{
Mapping of service deployment use cases and user requirements for an On-demand shared ride-hailing service: MOIA Test Service Case Study
}

\begin{abstract}
Demand Responsive Transportation (DRT) is currently growing in our cities as shared ride-hailing services operated by private companies, providing a hybrid service between the bus and the taxi. Like DRT, these new on-demand services could be used to feed and complement the public transport, and additionally, their flexibility might bring other market opportunities, beneficial to cities and metropolitan areas. However, the true potential of them, as well as the recognition of the service requirements depending on the type of user and use case, remains unstudied. Hence, the aim of this research is to identify user requirements and market opportunities, from the case study conducted with the participation of 1211 users of the MOIA service test in Hanover, to contribute to the successful design of this new generation of DRT. Results indicate a high interest in using MOIA for leisure trips, identify the highest intention of use of the service within suburban areas, and recognise a different behaviour, both in the intention of use and for user requirements, depending on the age of the users and the usage frequency.
\end{abstract}

\section{Keywords}

Demand Responsive Transportation; flexible transport; on-demand transport; shared mobility; ride-hailing; ridesharing 


\section{Introduction}

Demand Responsive Transportation (DRT) is still an underutilised mobility solution, despite being a cost-effective solution for many use cases (Interreg Europe, 2018). Also known as Flexible Transport Services (FTS) or paratransit services, it dates back to the late 1960s, when it was mainly used to provide a more economical public transport to suburban and rural areas (Rimmer et al., 1984). During the last ten years, this type of DRT has evolved from being a dial-a-ride service operated by Public Transport Operators or taxi companies to app-based services operated by Transportation Network Companies (TNCs).

Before the arrival of these app-based transport services, according to Enoch et al. (2004), DRT was used for four concrete purposes: to feed public transport (Interchange DRT), to enhance public transport (Network DRT), to serve a particular destination (Destination-specific DRT) and to substitute public transport (Substitute DRT). Enoch et al. (2004) analysed 74 different purpose services, from 1969 to 2004, and categorised them as public policy services, which covered low density areas in a more efficient way, such as the Phone and Go in Northumberland and the LinkUp in the county Tyne and Wear (Brake \& Nelson, 2007; Nelson \& Phonphitakchai, 2012); or commercially driven services, which covered strategic use cases such as the commuting or specific use cases like trips to and from the airport. In their work, Jain et al. (2017) focused not only on providing a transport service in underserved areas but also to minority disadvantaged groups, such as elderly, young and disabled people, without access to a motor vehicle and with low incomes. Finally, a more modern service, the Kutsuplus pilot in Helsinki, was analysed by Weckström et al. (2018). Kutsuplus enabled a pre-booking with less anticipation, up to 30 minutes before the trip, which could be requested via the website or SMS instead of per-call.

The progress of technology and the arrival of smartphones have enabled the deployment of modern DRT known as shared ride-hailing services in a variety of urban and suburban use cases, although they serve mainly high density areas without a concrete purpose. The ride-hailing service is similar to the taxi service, with the difference that pick-up street hails are not authorised without a previous booking. The singular model (singular ride-hailing) offers private rides, whereas the shared model matches users going to the same direction. This way, trip requests can be now made on-demand (instant pre-booking) through an application, and the routing and pricing are calculated on a real time basis. Most of the shared ridehailing services are commercially driven and operated by TNCs, such as uberPOOL, Chariot, Via or MOIA.

The importance of sharing rides has been highlighted in some simulation studies like: OECD (2015), which stated that in mid-sized European cities like Lisbon, the same mobility could be achieved with 10\% of cars if rides were shared, together with a high-capacity public transport; Alonso-Mora et al. (2017), who concluded that $98 \%$ of the taxi demand in New York could be covered using 2000 vehicles with capacity for 10 people or 3000 with capacity for 4 people, which was, respectively, $15 \%$ and $22 \%$ of the current taxi fleet; and Yu et al. (2017), who estimated that, in one year of sharing all the rides in Beijing, there would be direct energy savings, a reduction of 46.2 thousand tons of $\mathrm{CO}_{2}$ emissions and 235.7 tons of NOx emissions.

Apart from simulation studies, the research done so far on ride-hailing was mainly focused on the business model of Peer-to-Peer (P2P) services but without considering their shared option, i.e. on-demand private trips cheaper than taxi trips, provided for instance by Uber (Bonazzi \& Pigneur, 2015; Gao \& Zhang, 2016; Watanabe et al., 2016; Watanabe et al., 2017), Uber's surge pricing model (Chen et al., 2015; Hall et al., 2015), and their workforce and regulation (Hall \& Krueger, 2015; Rogers, 2015; Ross, 2015).

In spite of the benefits shown in simulations, DRT has still not taken off to its full potential. Hence, the aim of this research is to provide the main findings about user requirements and market opportunities to contribute to the successful design of the new generation of DRT, based on the service test launched by MOIA in Hanover. MOIA is the Volkswagen Group's mobility services company, currently operating a shared ride-hailing service in Hanover and Hamburg.

The rest of the paper is organised as follows: the second section provides an overview of the service design of DRT, the third section outlines the adopted case study and details the methodology used to 
conduct the research, and the fourth section presents the results of the case study. Finally, the conclusions are provided in section 5 .

\section{Literature review}

The appropriate deployment of shared ride-hailing services to maximise the benefits of cities, users and operators, as well as the identification of the user requirements depending on the use cases, remains unstudied. As most of the research done so far comes from the traditional DRT services, this literature review covers several key topics related to them as a basis for the current research.

The success factors identified to maximise the growth and opportunities of DRT are, according to Enoch et al. (2004) and Brake \& Nelson (2007), the need of good partnerships, to identify and understand real user requirements, and effective marketing to potential users. Weckström et al. (2018) specified that marketing should be educational on the use of service, and confirmed the importance of identifying the end user target group. Besides, Davison et al. (2012) highlighted the need of collaboration among all stakeholders and the redefinition of their current roles in DRT, and the technological advancements. Already in 2004, when it was not yet known that the arrival of the smartphone would revolutionise the market of the commercially driven DRT, Enoch et al. (2004) identified the progress of technology (i.e. advances in digital maps, GPS technologies and internet) as a key factor for the growth of such services. Apart from that, the authors noted the risk of failure due to not having a balanced flexibility and a realistic costing. Later, Davison et al. (2012) also highlighted the key role of technological advancements, specifically, in programming and software, availability of smartphones and cloud computing. In particular, Hosny \& Mumford (2009) and Basnal et al. (2015) categorised the efficient routing and grouping algorithm as a crucial part of the DRT. Furthermore, Weckström et al. (2018) suggested to improve the usability of DRT by the integration into the public transport fare system, in the direction of the Mobility as a Service (MaaS) concept. On the other hand, Enoch et al. (2004) also identified the following barriers: call centres operational costs, the lack of legislation, funding and political support, the absence of mobile telephone coverage in some rural areas, and the resistance to ride-sharing.

Highly valued design factors from users' perspective are, by Enoch et al. (2004), the certainty of arrival time, being a door-to-door service, the price and the vehicle comfort. However, the importance of these factors was found to depend on the type of user and use case. For instance, users with access to a car higher valued a door-to-door service and the vehicle comfort, whereas users without access to it gave more importance to the price. Moreover, Enoch et al. (2004) recommended to not forget the factors required to increase the modal shift such as the good reliability, accessibility, frequency, cleanliness, vehicle heating and cooling, being easy to understand, and having friendly and helpful staff. Nelson \& Phonphitakchai (2012) also stated that informing the fixed time of arrival and being door-to-door is important, mainly for the elderly and also during the night, and that negative experiences were related to the booking system or journey problems. Finally, Brake et al. (2004) added that the fare structure should be easy to understand; discussed that some service and vehicle characteristics might be compromised such as the vehicle low floor design, which could be suitable for passengers but not for rural roads-; and suggested that the integration with all public transport services would help DRT to be more economically sustainable.

Concerning the user requirements, Weckström et al. (2018) found that a lower price than the taxi was the main reason of Kutsuplus riders to use this DRT, followed by the speed in comparison to public transport, due to the lack of good public transport connection, the ease of ordering a trip, and lastly, problems related to the use of the personal car such as the lack of parking spaces. On the other hand, users who stopped using Kutsuplus left the service due to the complexity of the booking and paying fare, the high cost, the long walking distance to the pick-up/drop-off point, and because they used other public transport means. In addition, Weckström et al. (2018) identified that the users did not like to prepay the trips, and that they would have liked that the service covered the whole urban area of Helsinki, including the airport.

Regarding market opportunities, Enoch et al. (2004) identified that the most suitable use cases for using a DRT are shopping, health and leisure trips. Nelson \& Phonphitakchai (2012) stated that LinkUp was mainly used for leisure trips, and other uses were shopping, entertainment, friends, relative visits, 
health visits, and commuting. Social or recreational was as well the most common trip purpose of Kutsuplus, followed by commuting (work/school), business, and lastly, shopping (Weckström et al., 2018). In addition, the authors stated that most of the rides were individual, and were conducted in the afternoon and evening. Besides, Kutsuplus was also appreciated for being a safe evening/night transport, and a safe transport for children to travel alone to their hobbies or school. Finally, Ryley et al. (2014) analysed six market niches for a DRT: rural hopper, shopping services, airport access, station access, employment shuttle, and hospital access. From a viability analysis point of view, they concluded that only the airport and station access DRT could be financially viable, linking their success to the destinations' parking cost and availability, important for the commuting and business use cases.

It is worth mentioning that new app-based shared ride-hailing services, although they usually cover high density zones such as city centres, in some occasions they provide as well a transport solution at a low investment to peripheral neighbourhoods with inefficient access to public transport, like the first diala-ride services. For instance, Morozov (2016) explained that some U.S. local administrations asked Uber -in exchange for significant subsidies- to assume public transport functions in areas where infrastructure was poor; Bliss (2018) reported partnerships of public transport authorities with different TNCs to supply Interchange DRT, Network DRT, Substitute DRT, and also DRT to non-emergency 911 calls; and Watanabe et al. (2017) remarked that in countries like Saudi Arabia, Uber offered reliable transportation to women, thus enabling them to have jobs. Therefore, market niches could be either public policy or commercially driven, or a combination of both.

This review sheds light on design factors, user needs and market opportunities for DRT deployment, which can be a base for the design of shared ride-hailing services. However, on-demand shared ridehailing provides more use cases than traditional DRT, therefore, it is necessary to identify not only which use cases might have a higher usage rate, but also whether the design factors depend on the type of users and use cases.

\section{Case study and methodology}

The case study analysed was the MOIA service test based in the German city of Hanover, covering an area of 90 square kilometres (Figure 1). Hanover has a population of 535603 inhabitants, which together with its area of influence -the 21 surrounding municipalities- totals almost 1.2 million (Region Hannover, 2018). The city receives a daily number of work-commuters equivalent to $32.8 \%$ of its population, the large majority of work-commuters living in the city remain in the city (70.3\%), and $29.7 \%$ work outside the city (Elmer et al., 2018).

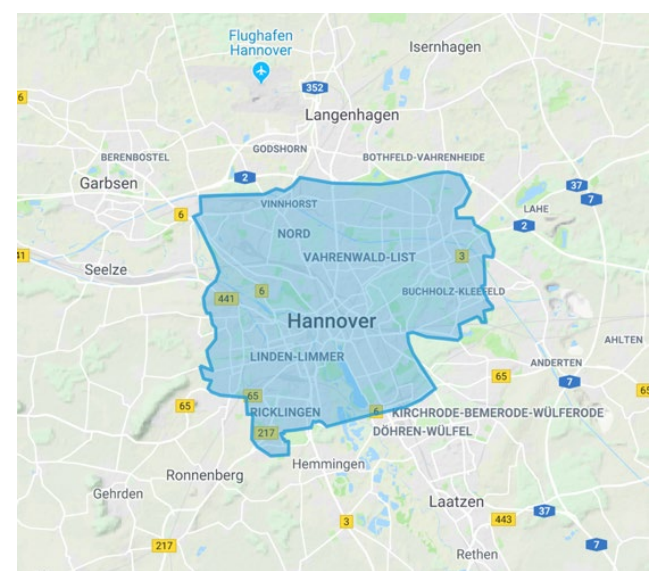

Figure 1. Service area of MOIA in Hanover (MOIA, 2018).

Inhabitants of Hanover region make almost half of all everyday journeys on foot, by bicycle or by public transport (Region Hannover, 2018). In the city of Hanover, 20\% of the population travels by bicycle and another $20 \%$ by public transport; whereas in the surrounding area, both the use of the bicycle and the public transport drops to 10\% (Region Hannover, 2018). The public transport network of the city consists of light rail vehicles (Stadtbahn) that cover different parts of the city, S-Bahn and regional trains 
to connect with the surrounding areas, and metropolitan and regional buses to complement the local rail transport. Furthermore, alternative means such as Business-to-Consumer (B2C) and P2P carsharing (car rental service per hours or minutes), and ridesharing (service to share regular trips or punctual long trips in order to share the costs, also known as carpool), are also available.

MOIA service test started the $4^{\text {th }}$ October 2017 and ended the $28^{\text {th }}$ July 2018, after 300 days of testing and recording a total of 230000 rides. Due to the German regulatory framework for noncommercial services, the price was limited to 0.06 euro $/ \mathrm{km}$ per person. The service was provided ondemand, therefore users could not pre-book their trips in advance; and corner-to-corner, which means that the pick-up and drop-off spots were up to 250 meters far from the addresses specified by the users. The test was offered to 3906 testers, who previously expressed their interest to become testers through the service website. The vehicle fleet grew from 20 to 35 dark-blue Volkswagen T6 vans, with a seating capacity of 5 people plus the driver. The service times were from Monday to Thursday 05:00-24:00, Friday 05:00-03:00, and Saturday 10:00-03:00.

To request a ride, users were required to previously download the MOIA app -through an invitation-, open it and fill in some personal information as well as the payment details. During the usage, they were asked to specify the trip origin and destination, and the number of people travelling. In case of availability, the app showed the pick-up time and location, the estimated time of arrival, the drop-off location, and the cost of the trip. At that point, users could either book the seats or reject the offer. During the ride, users could follow the progress of their trips through the app, and could also monitor on the invehicle display the intermediate stops that would be made so that other passengers could be picked-up and dropped-off.

To have a broad understanding of the user requirements and use cases for on-demand shared ridehailing services, the service test of MOIA was analysed through an online survey participated by 1211 registered users. This quantitative study was conducted between the $28^{\text {th }}$ June and the $16^{\text {th }}$ July 2018 , applying a structured on-line survey with mainly closed-ended questions. The questionnaire was structured in 5 blocks, as shown in Figure 2: 1) classification questions, 2) commuting (i.e. trips to and from work or university), 3) personal mobility (i.e. all trips except business and commuting) and intention of use of shared mobility services for personal and occupational mobility, 4) experience with MOIA, and 5) reasons to not use MOIA.

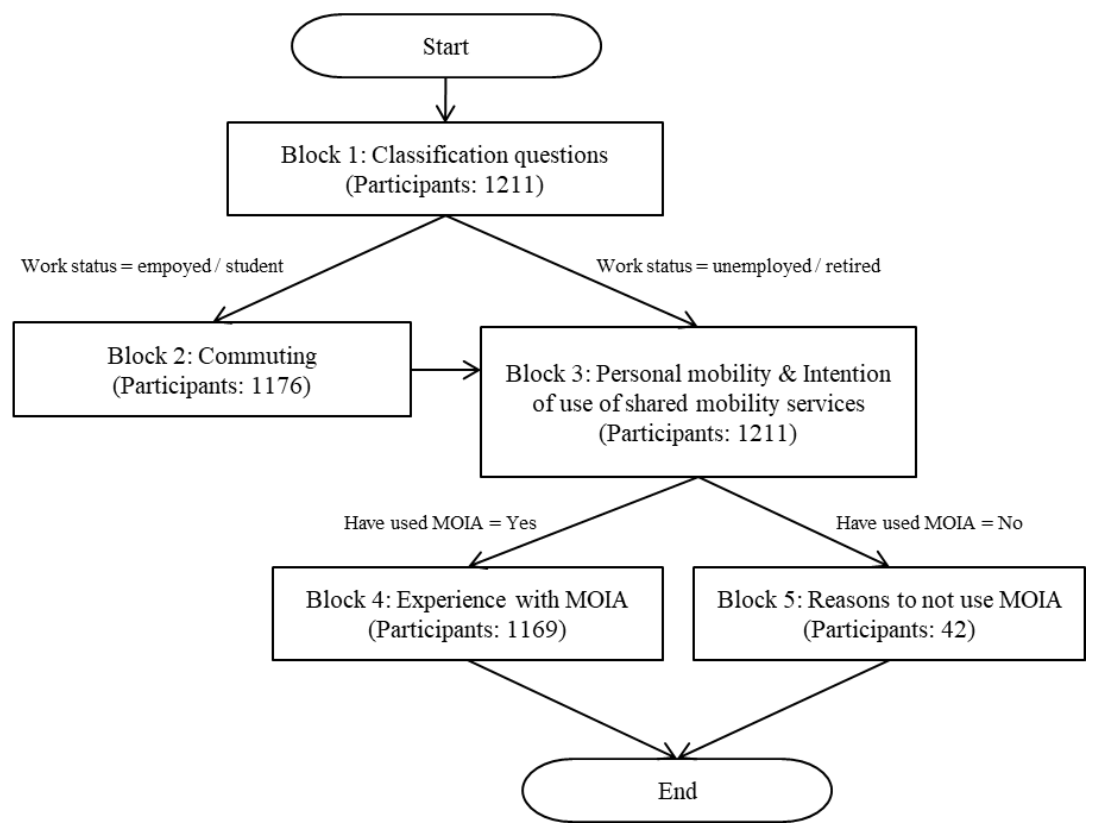

Figure 2. Structure of the survey.

The first block of the survey asked the gender, age and location of participants, as well as if they had a driving license, and a car or a scooter at their disposal. The second block focused on the commuting trips, since it was one use case intended to explore for a twofold reason: due to the traffic linked to it, and 
therefore, the potential that shared mobility services have to reduce it; and because commuters would be regular users, making at least 2 trips per day. Participants were asked about their commuting destination (Hanover, surroundings of Hanover, or outside this area), the one-way trip length, and the means of transport used (multiple choice question). Non-commuters were excluded from block 2 and were directed to block 3. All questions from the third block were multiple choice, and asked, on one hand, the means of transport used for individual private trips and private trips with family or friends; and on the other hand, the intention of use, in different use cases, of the following shared mobility services: MOIA, singular ride-hailing, P2P ridesharing, and carsharing. All these services were explained in detail and with examples, however the respondents had experience using MOIA and only a few using the other services. Finally, the fourth block was about the frequency of MOIA usage and the improvements that would be required to increase the usage rate, in two scenarios: "study and work scenario" and in a "social" (multiple choice questions). Since the survey was sent to all registered testers, and it was important that block four was only answered by the participants, who, at least, had used the service once, a decision question was applied at the end of the third block. Participants excluded from the fourth block were directed to the fifth block, in which they were asked the reasons for not trying MOIA with an open-ended question.

\section{Analysis of results}

In this section, the results from the conducted survey are analysed. First, the participants' profile is presented. Then, the operational context is explored through the analysis of participants' mobility patterns, and market opportunities are evaluated through their intention of use of MOIA for different use cases. Finally, user requirements are prioritised according to users' profile and the use cases.

\subsection{Participants' profile}

The respondents profile is described in Table 1. Most of the participants were men, aged between 30 and 45, employed, and living in Hanover, which coincided with the profile of the total number of registered test users. $96 \%$ of respondents had a driving license, $75.1 \%$ had access to a car, and $13.7 \%$ to a motorcycle, owned or from a family member.

Table 1. Respondents' profile.

\begin{tabular}{llc}
\hline Classification variables & Stated answers & No. of responses \\
\hline Gender & Men & 817 \\
Age & Women & 394 \\
& $18-29$ & 349 \\
& $30-45$ & 526 \\
Driving license & $46-65$ & 319 \\
& +65 & 17 \\
Car at disposal & Yes & 1163 \\
Motorcycle at disposal & No & 48 \\
& Yes & 910 \\
Place of residence & No & 301 \\
& Yes & 166 \\
& No & 1045 \\
Work status & City & 1088 \\
& Surroundings & 74 \\
& Region or further & 49 \\
& Employed & 930 \\
& Self-employed & 99 \\
& Students & 147 \\
& Unemployed & 18 \\
& Retired & 17 \\
\hline
\end{tabular}

\subsection{Participants' mobility patterns}

The majority of MOIA users were using the service on all days of the week (76.8\%), 15.5\% used it only on weekdays, and the remaining $7.7 \%$ only at weekends. Regarding the frequency of usage, $44.7 \%$ used it more than once per week (out of which, $12.5 \%$ used it on a daily basis or almost daily), $44.9 \%$ 
from 1 to 4 times per month, and the rest $10.4 \%$, rode with MOIA less than once per month. To identify which variables were significant, a Pearson chi-square analysis at $95 \%$ confidence level $(p$-value $<0.05)$ was conducted. The analysis revealed that there was a significant association between most of the classification variables (gender, age, driving license, car at disposal, place of residence, and work status) and MOIA usage (see Table 2, $p$-value $<0.05$ marked with *). Regarding these significant variables, from the statistics of use we observe that participants using the service more frequently were men, the 18 to 29 year-old segment, participants without the driving license, participants without access to a car, those living in Hanover, and students.

Table 2. Pearson Chi-square test for association of MOIA usage frequency with classification variables.

\begin{tabular}{lc}
\hline Classification variables & p-value \\
\hline Gender & $0.004 *$ \\
Age & $0.002 *$ \\
Driving license & $0.000 *$ \\
Car at disposal & $0.000 *$ \\
Motorcycle at disposal & 0.086 \\
Place of residence & $0.000 *$ \\
Work status & $0.000 *$ \\
\hline \multicolumn{2}{c}{$*$ Significant variables }
\end{tabular}

Participants' use of different means of transport for "commuting", "individual private trips" and "private trips with family or friends" is shown in Figure 3.

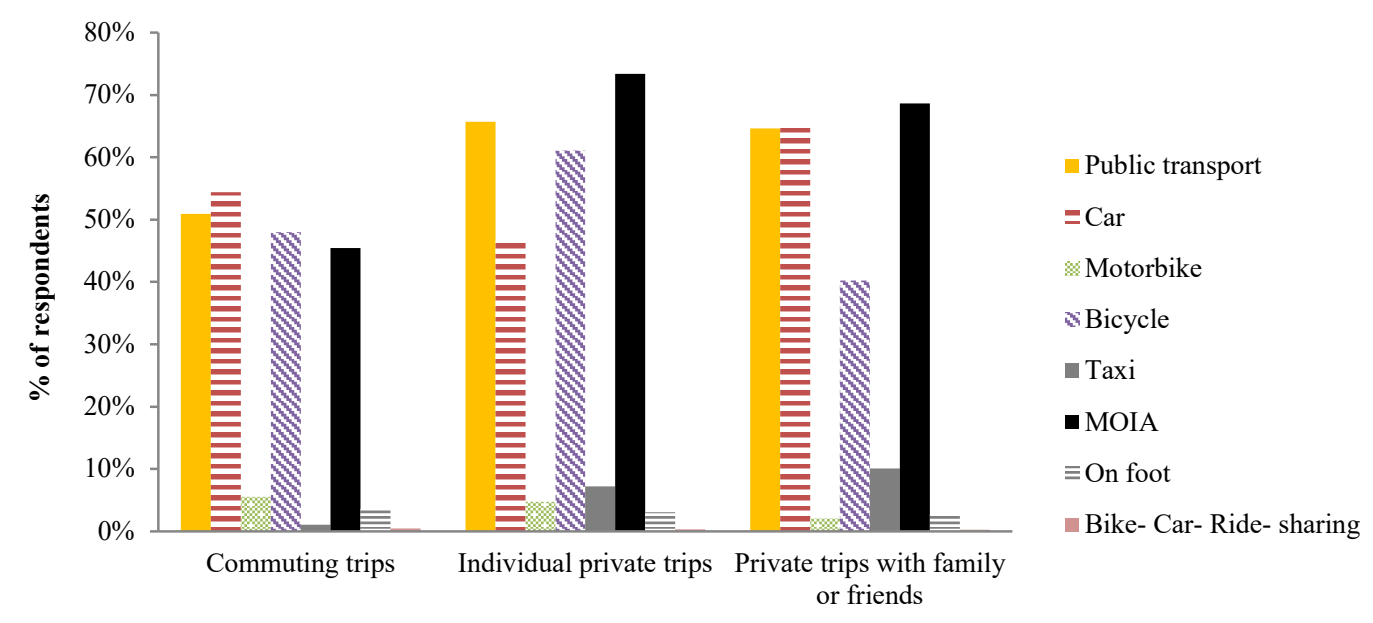

Use case

Figure 3. Means of transport used to commute (total commuters: 1165), travel within the city for personal reasons alone, or with family and friends (total participants: 1211).

This comparison indicates that for personal mobility (private trips alone or with family or friends) participants used more MOIA and public transport and were also more multimodal (not always taking the same means of transport to get to the destination) than for commuting. For instance, some interviewees commented that they commuted by bicycle except when the weather was bad, then they used MOIA; or that they used MOIA as a feeder service to metro or train stations, and then took the suburban trains/metros for further part of the journey. The use case with a higher usage rate of MOIA was "individual private trips", which was also the case in which both the public transport and the bicycle were used more, and the one with the lowest car use. That could be related to the fact that the cost of travelling by car alone within the city is expensive and sometimes also slow due to the traffic and the time required for finding a parking spot. In the case "private trips with family or friends", the use rate of MOIA was very similar to both the use rate of public transport and the private car. This means that the private car was sometimes more convenient than public transport when the rides were shared with the family -e.g. travelling with children with their prams- or with friends, then the costs of travelling by car were not so high since they could be shared. Therefore, shared ride-hailing services adapted to the needs of this type 
of users have the chance to substitute some of these private car trips. In reference to the use case "commuting", the main means of transport used by participants were the private car, followed by the public transport, the bicycle, and MOIA. The highest use of the car was to commute within the surroundings, from the region or a further location to the surroundings, and from the surroundings to Hanover $(81.2 \%, 80.6 \%$ and $78.2 \%$ respectively). In these situations, the use of the car surpassed by $40 \%$ the use of public transport, since in most cases, these trips did not have a direct public transport connection, were too long to be covered by bike, and were out of MOIA's coverage area. Hence, shared ride-hailing services covering this type of trips could have a high impact on reducing private car trips, without affecting other sustainable transport modes.

Focusing on the use of MOIA, a statistical analysis was done to identify significant associations between the classification variables and the MOIA real use. Significant variables at $95 \%$ confidence level are, in all three use cases, the age, having a driving license, and the place of residence (see Table 3 ).

Table 3. Pearson Chi-square test for association of MOIA real use with classification variables.

\begin{tabular}{lccc}
\hline Classification variables & $\begin{array}{c}\text { Commuting } \\
\boldsymbol{p} \text {-value }\end{array}$ & $\begin{array}{c}\text { Individual private tripss } \\
\boldsymbol{p} \text {-value }\end{array}$ & $\begin{array}{c}\text { Private trips with family or friends } \\
\boldsymbol{p} \text {-value }\end{array}$ \\
\hline Gender & 0.186 & 0.348 & 0.254 \\
Age & $0.003^{*}$ & $0.000^{*}$ & $0.000^{*}$ \\
Driving license & $0.000^{*}$ & $0.010^{*}$ & $0.011^{*}$ \\
Car at disposal & $0.006^{*}$ & 0.131 & 0.101 \\
Motorcycle at disposal & 0.099 & 0.062 & 0.154 \\
Place of residence & $0.000^{*}$ & $0.001^{*}$ & $0.000^{*}$ \\
Work status & $0.007^{*}$ & 0.274 & $0.036^{*}$ \\
\hline & & & $*$ Significant variables
\end{tabular}

In these situations, the segments with a declared higher use were: the 18 to 29 year-old group (up to $26 \%$ more than the oldest group, since the use gradually decreased as the age increased), participants without the driving license (29\% more for "commuting" and $17 \%$ more for "private trips", compared to participants having the driving license), and participants living in Hanover due to the service only being available in Hanover (the most notable difference being in the use cases of "commuting" and "private trips with family or friends"). Additionally, for the "commuting", participants without access to a car used more MOIA than participants with access to it, and students also declared a higher use of the service for this use case as well as for "private trips with family or friends". Therefore, it is found that younger citizens were more opened to use this type of service. Among them, those being students, without a driving license, or without access to a car.

\subsection{Intention to use the MOIA service}

Since the test service was limited both in the service area and service hours, to better understand in which situations users would use a shared ride-hailing service, MOIA test users were asked about their usage intention of the service according to 9 different use cases. In addition, they were also required to state their usage intention, for the given cases, of other new mobility services: P2P ridesharing, carsharing, and singular ride-hailing. As shown in Figure 4, the intention to use MOIA was the highest for 7 of the 9 use cases. Only "for day trips" and "business trips" participants would prefer taking a carsharing, or also a singular ride-hailing service in the case of "business trips". The use cases with the highest intended use of MOIA came from: "to come home alone after going out" (93.4\%), "to go out with family/friends" $(81.9 \%)$, "to get to or from the airport" $(78 \%)$, "to commute" $(66.3 \%)$, and "to go shopping alone" (49.4\%). Participants also proposed concrete use cases, such as trips to and from the train station, visits to doctors, and to go to certain events (concerts, festivals, etc.), as well as general uses such as trips to the city centre and outside the city. Compared to the use cases found in the literature review, these results confirm that shared ride-hailing is a suitable mean of transport for leisure trips, and also to potentially act as a feeder service to mass transport. 


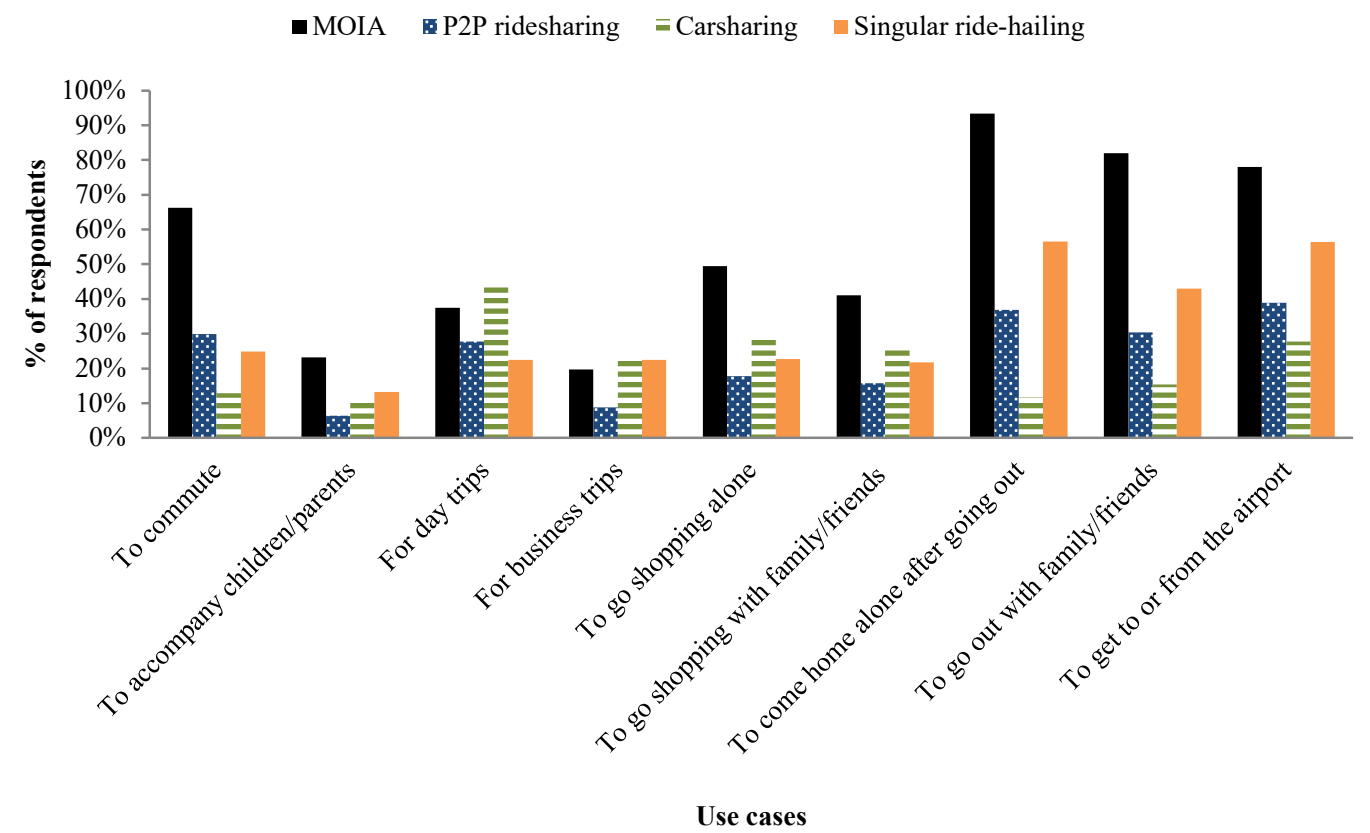

Figure 4. Intention of use of MOIA in comparison to P2P ridesharing, carsharing, and singular ride-hailing

With the aim of finding out the target users of the use cases with a usage intention of MOIA similar or higher than 50\%, we conducted the Pearson chi-square analysis shown in Table 4 . In this analysis, the variable usage frequency related to the participants' real use of MOIA (more than one use per week, less than one use per week, never used) was also considered. Firstly, for the case "to come home alone after going out", the variables age and work status are relevant: participants older than 65 years -and retireddeclared up to $23 \%$ lower intention of use in comparison to the other age and work status groups. Secondly, for the case "to go out with family and friends", the significant variables are age and usage frequency: the oldest segment declared again a lower usage intention (16\% lower than the 18-29 year-old group, and 10\% lower than the groups 30-45 and 46-65), and, regarding the usage frequency, non-users of MOIA expressed 18\% lower intention of use than the MOIA users. Gilibert et al. (2017) already stated that citizens without a previous use of this type of services were more reluctant to use them. Moreover, "to get to or from the airport" was also a more interesting use case for the citizens up to the age of 65, neither retired nor unemployed, and even a little more attractive for participants with access to a car. Besides, the greatest usage intention "to commute" was given by participants who did not have a driving license, residents of the vicinity of Hanover -where the MOIA service was not available-, and the already frequent users of MOIA. Furthermore, the highest interest in "to go shopping alone" was expressed by women (11\% higher than men), participants without access to a car, and frequent MOIA users.

Table 4. Pearson Chi-square test for association of the situations with the highest usage intention of MOIA.

\begin{tabular}{|c|c|c|c|c|c|}
\hline Variables & $\begin{array}{c}\text { To come home alone } \\
\text { after going out } \\
p \text {-value }\end{array}$ & $\begin{array}{c}\text { To go out with } \\
\text { family/friends } \\
\text { p-value }\end{array}$ & $\begin{array}{c}\text { To get to or } \\
\text { from the airport } \\
\text { p-value }\end{array}$ & $\begin{array}{c}\text { To commute }{ }^{\chi} \\
\text { p-value }\end{array}$ & $\begin{array}{c}\text { To go shopping } \\
\text { alone } \\
\text { p-value }\end{array}$ \\
\hline Gender & 0.214 & 0.140 & 0.471 & 0.424 & $0.000^{*}$ \\
\hline Age & $0.001 *$ & $0.027 *$ & $0.000 *$ & 0.225 & 0.292 \\
\hline Driving license & 0.198 & 0.903 & 0.391 & $0.014 *$ & 0.119 \\
\hline Car at disposal & 0.440 & 0.657 & $0.029 *$ & 0.612 & $0.021 *$ \\
\hline Motorcycle at disposal & 0.676 & 0.130 & 0.904 & 0.442 & 0.406 \\
\hline Place of residence & 0.139 & 0.793 & 0.353 & $0.031 *$ & 0.646 \\
\hline Work status & $0.001 *$ & 0.300 & $0.015^{*}$ & 0.772 & 0.177 \\
\hline Usage frequency & 0.577 & $0.006^{*}$ & 0.125 & $0.000 *$ & $0.001 *$ \\
\hline
\end{tabular}

$\chi$ Test conducted with the commuter user base (1165 participants) 
The survey analysis revealed, on one hand, that the most suitable scenarios for an on-demand shared ride-hailing service from the users' point of view were: 1) leisure and shopping activities, especially for individual travellers; 2) commuting as a complement of the public transport, reaching areas which are not efficiently covered by this means or as a feeder of it; 3 ) direct connection to the airport. These three uses would be compatible with each other, since commuting takes place in peak hours, whereas leisure and shopping activities go on mainly during off-peak hours, and transfers to the airport run all day. The combination of these services would ensure a minimum occupancy rate of the car during the day, and maximise the profitability of the service.

\subsection{User requirements}

In this section we analyse the most important service requirements from users' perspective. In particular, we compare the requirements in two different scenarios: "study and work scenario" (i.e. commuting and business trips) and "social scenario" (i.e. travelling with family and friends). Since the aim of this part of the questionnaire was to find out the user requirements of a shared ride-hailing service based on the experience of the users of such a service, the respondents without this experience were excluded from this part. Consequently, the total number of participants for this part was reduced to 1169 .

Although the survey participants were registered as MOIA test users, 3.5\% of respondents had not used the service before answering this survey. The main reason for not having tried it was due to their origin or destination being outside the area.

Participants were asked to value, on a scale of 1 to 5, 16 hypothetical improvements that would make them use the service more often for "study and work related trips", and for travelling with family and friends.

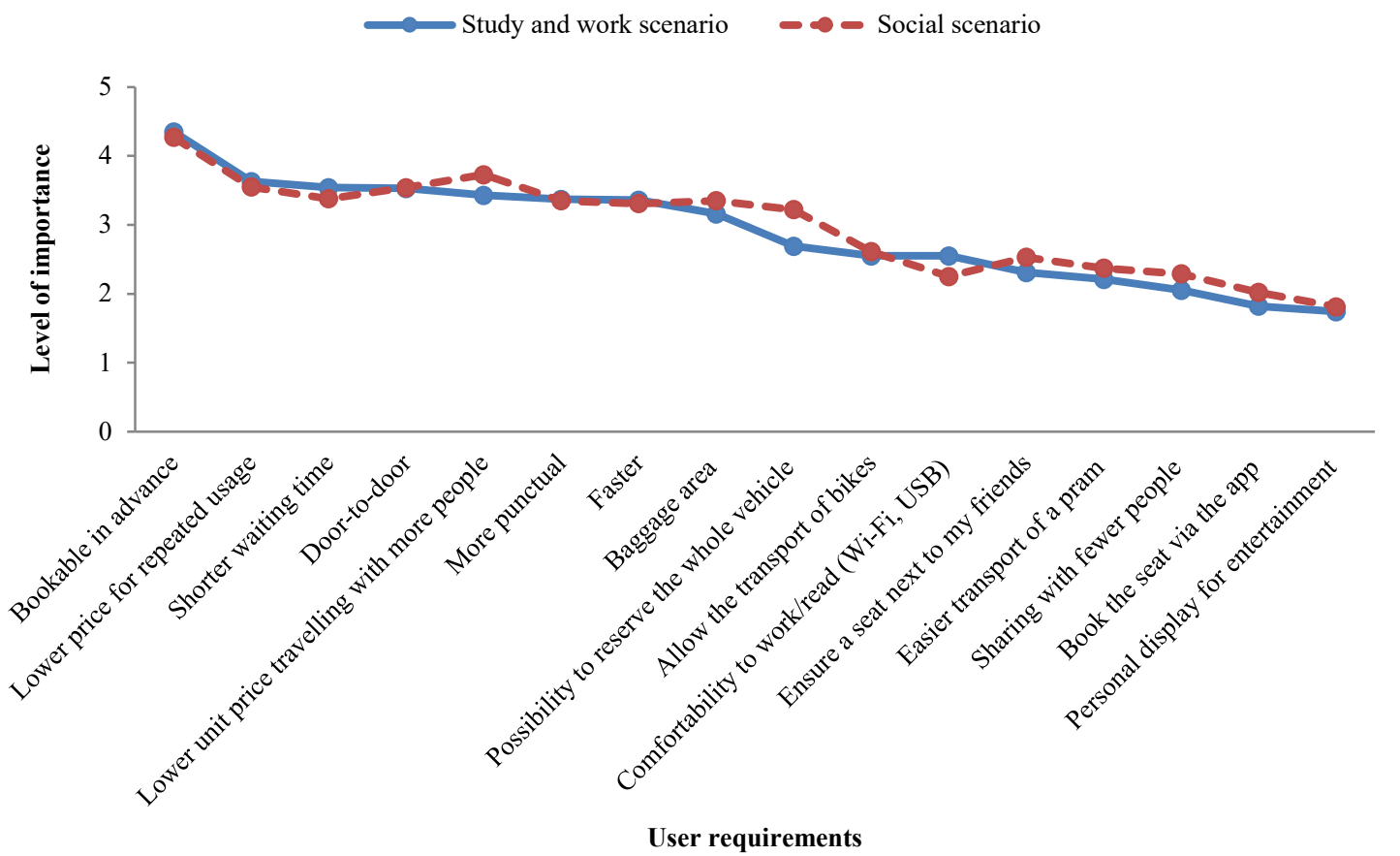

Figure 5. Answers to the question "I would use MOIA more often if..." in a "study and work scenario" vs. "social scenario".

From the results presented in Figure 5, which are sorted by the level of importance, one can observe that in both situations users wanted optimised waiting and travel times, and a competitive price for repeated usage and for travelling with more people. Besides, they also needed to feel safe and secure during the whole customer journey, i.e. from the booking to reaching the final destination. Less voted were the topics corresponding to comfort elements. Among them, the most valued were to have a baggage area -mainly related to the shopping and going to the airport use cases-; the possibility to reserve the whole vehicle -suitable for travelling with family and friends, since by not sharing with other users 
detours would be avoided and talks could be held without disturbing anybody-; to enable the carriage of bicycles on board -suitable for users wanting to pedal the first and last mile of their trips-; to offer Wi-Fi and USB chargers -slightly more important for the commuting use case-; and to ensure that the seats of the companions are together -suitable for trips with more people, especially in the case of families travelling with children-. The remaining topics had a level of importance of less than 2.5 points for both use cases. The reasons behind not giving so much importance to these topics were, in the case of the easier transportation of a pram, that it was not a general need; sharing the vehicle with less people was not the purpose of this business model, and users understood it; and reserving a seat via the app and having a personal display for entertainment were not seen as requirements since trips were relatively short. Participants proposed other improvements related to the service expansion, the accuracy and usability of the app, the navigation (more efficient and less derouting), and better calculation of the pick-up and dropoff times.

The comparison between the two scenarios shows that the importance given to the requirements is quite similar (Figure 5). Given these results, it should be noted that the key design factors for a shared ride-hailing service are:

- The reliability and availability: users asked for pre-booking to be sure that they would receive a ride at the desired time.

- The price, which should be competitive in the focused use cases -despite the low cost of the service test, the two improvements regarding the price calculation were highly voted-.

- The waiting and travel times: users do not want to wait and want to reach their destination quickly and on time.

- Short walking distance to the pick-up point and from the drop-off point to the final destination: users highly valued a door-to-door service to save the time of walking; for a better comfort in case, for example, of bad weather or travelling with baggage; and for safety, mainly in the case of night trips.

By means of the Pearson chi-square test, we analysed the significant associations between the demographic and behavioural variables and the most valued user requirements for both scenarios. Before, to have enough answers in each group, we converted the responses from the 5-point scale to a 3-point scale: not agree (1-2), not sure (3), agree (4-5). First, the analysis of the requirements related to the "study and work scenario" with the commuter user base is presented (1126 participants, since those without experience riding with MOIA were excluded). In this analysis (Table 5), we also considered the variables associated to MOIA user to commute (yes, no), car user to commute (yes, no), and Public Transport (PT) to commute (yes, no), to explore if users of each of these means of transport had different requirements.

Table 5. Pearson Chi-square test for association of the most valued requirements in a "study and work scenario".

\begin{tabular}{|c|c|c|c|c|c|c|c|}
\hline Variables & $\begin{array}{c}\text { Bookable in } \\
\text { advance } \\
\text { p-value }\end{array}$ & $\begin{array}{c}\text { Lower price } \\
\text { for repeated } \\
\text { usage } \\
p \text {-value }\end{array}$ & $\begin{array}{c}\text { Shorter } \\
\text { waiting } \\
\text { time } \\
\text { p-value }\end{array}$ & $\begin{array}{c}\text { Door- } \\
\text { to-door } \\
\text { p-value }\end{array}$ & $\begin{array}{c}\text { Lower price - } \\
\text { trips with } \\
\text { more people } \\
\text { p-value }\end{array}$ & $\begin{array}{c}\text { More } \\
\text { punctual } \\
\text { p-value }\end{array}$ & $\begin{array}{l}\text { Faster } \\
\text { p-value }\end{array}$ \\
\hline Gender & 0.381 & 0.595 & 0.731 & 0.128 & 0.870 & 0.630 & 0.647 \\
\hline Age & 0.073 & $0.000 *$ & $0.000 *$ & 0.243 & $0.019 *$ & $0.000 *$ & $0.000^{*}$ \\
\hline Driving license & 0.813 & 0.867 & 0.842 & 0.981 & 0.533 & 0.891 & 0.723 \\
\hline Car at disposal & 0.439 & 0.593 & 0.066 & 0.182 & 0.595 & 0.193 & 0.550 \\
\hline Motorcycle at disposal & 0.437 & 0.279 & $0.039 *$ & 0.190 & 0.860 & 0.121 & $0.041 *$ \\
\hline Place of residence & 0.847 & 0.831 & 0.742 & $0.000 *$ & 0.981 & 0.735 & 0.739 \\
\hline Work status & 0.749 & 0.096 & $0.019 *$ & 0.393 & 0.070 & $0.007 *$ & 0.591 \\
\hline MOIA usage frequency & 0.614 & $0.000 *$ & $0.036^{*}$ & 0.287 & $0.003 *$ & $0.000 *$ & 0.079 \\
\hline MOIA user to commute & 0.524 & $0.001 *$ & 0.496 & 0.088 & $0.012 *$ & $0.004 *$ & 0.219 \\
\hline Car user to commute & 0.568 & 0.850 & 0.162 & $0.013^{*}$ & 0.720 & 0.662 & 0.984 \\
\hline PT user to commute & 0.933 & 0.076 & 0.076 & 0.285 & 0.244 & $0.015^{*}$ & 0.082 \\
\hline
\end{tabular}

In this scenario, the variables place of residence and car user to commute are significant for the door-to-door service. Car users stated $8 \%$ more interest than non-car users -possibly as they are accustomed to car trips being door-to-door-; and residents around Hanover stated $26 \%$ more interest than residents of the city, and $18 \%$ more interest than participants from the region or further. In relation to the 
work status, students gave approximately $15 \%$ more importance to time-related requirements than participants who were employed or self-employed.

Next, the analysis of the requirements related to the "social scenario" is presented in Table 6 . In this case, to also find out if users of different modes of transport have distinct demands, we considered the variables MOIA user for trips with more people (yes, no), car user for trips with more people (yes, no), PT user for trips with more people (yes, no).

Table 6. Pearson Chi-square test for association of the most valued requirements in a "social scenario".

\begin{tabular}{|c|c|c|c|c|c|c|c|}
\hline Variables & $\begin{array}{c}\text { Bookable in } \\
\text { advance } \\
p \text {-value }\end{array}$ & $\begin{array}{c}\text { Lower price } \\
\text { if repeated } \\
\text { use } \\
p \text {-value }\end{array}$ & $\begin{array}{c}\text { Shorter } \\
\text { waiting } \\
\text { time } \\
\text { p-value }\end{array}$ & $\begin{array}{c}\text { Door- } \\
\text { to-door } \\
\text { p-value }\end{array}$ & $\begin{array}{c}\text { Lower price } \\
\text { - trips with } \\
\text { more people } \\
\text { p-value }\end{array}$ & $\begin{array}{c}\text { More } \\
\text { punctuality } \\
\text { p-value }\end{array}$ & $\begin{array}{l}\text { Faster } \\
\text { p-value }\end{array}$ \\
\hline Gender & 0.217 & 0.888 & 0.418 & 0.051 & 0.793 & 0.321 & 0.459 \\
\hline Age & $0.020 *$ & $0.000 *$ & $0.000 *$ & 0.441 & $0.000 *$ & $0.000 *$ & $0.000 *$ \\
\hline Driving license & 0.959 & 0.722 & 0.166 & 0.614 & 0.238 & 0.120 & 0.618 \\
\hline Car at disposal & 0.665 & 0.951 & 0.616 & 0.188 & 0.910 & 0.099 & 0.978 \\
\hline Motorcycle at disposal & 0.668 & 0.845 & 0.754 & 0.572 & 0.918 & 0.185 & 0.517 \\
\hline Place of residence & 0.973 & 0.878 & 0.392 & 0.000 & 0.934 & 0.777 & 0.589 \\
\hline Work status & 0.515 & 0.204 & $0.012 *$ & 0.846 & $0.013 *$ & $0.040^{*}$ & 0.118 \\
\hline MOIA usage frequency & 0.267 & $0.001 *$ & 0.068 & 0.614 & $0.005 *$ & $0.022 *$ & $0.013^{*}$ \\
\hline MOIA user for trips with more people & $0.041^{*}$ & 0.203 & $0.001 *$ & $0.011^{*}$ & 0.972 & 0.159 & 0.104 \\
\hline Car user for trips with more people & 0.232 & 0.134 & $0.036^{*}$ & 0.388 & 0.734 & 0.663 & 0.887 \\
\hline PT user for trips with more people & 0.859 & 0.145 & 0.111 & 0.462 & 0.141 & 0.189 & 0.786 \\
\hline
\end{tabular}

In the "social scenario", retired participants stated about $30 \%$ less interest of time-related requirements compared to the other work situations. However, these results would be influenced by the age factor, since students were the youngest participants, and in general, the 18-29 year-old segment was the most demanding; and retired participants were older than 65, the least demanding age group. Besides, the variable of MOIA user for trips with more people is significant for the requirements of pre-booking, shorter waiting time, and door-to-door service -being the users more interested in the pre-booking and having a shorter waiting time, and less interested in a door-to-door service-.

By comparing both tables, we found that the gender, driving license, and car at disposal are not significant variables in any of the scenarios. Conversely, the variable age is significant in most of the requirements in both scenarios, and in all cases following the same pattern: the age segments 18-29 and 30-45 indicated a greater interest than the segments 46-65 and over 65, being the oldest group the least demanding. The variable usage frequency (in this case: more than one use per week, or less than one use per week) is significant in 4 of the 7 requirements in both analyses, 3 of which are common in the two scenarios: the punctuality (daily and weekly users agreed with it $16 \%$ more in the "study and work scenario" and 8\% more in the "social scenario" than participants with less usage of the service), and the two related to offering a lower price (frequent users valued them about $10 \%$ more in both scenarios). For these three requirements, the variable MOIA user to commute is also significant in the "study and work" scenario, since it is related to the frequency of use. Also noteworthy is the significance of the work status in both scenarios for the time-related requirements: less waiting time and punctuality.

\section{Conclusions}

The MOIA test service enabled us to identify and analyse the most suitable use cases for on-demand shared ride-hailing services, as well as to better understand the users and their requirements. Like the traditional DRT, shared ride-hailing could be used as a feeder service to enhance and complement the public transport system, but, moreover, its flexibility brings other market opportunities which are beneficial to cities, metropolitan areas, and the same operators. In this regard, the use of the service for various purposes at different times of the day would guarantee a minimum occupancy rate and maximise the profitability of the service. Participants used MOIA, mainly, for private trips, but nearly half of them also used it to commute on a daily basis. Therefore, this type of service proved to be also convenient for this use case, which is the most helpful to reduce the number of private cars at peak times. Moreover, a need of a direct and flexible transport alternative to the car was mainly detected in suburban area of 
Hanover. In this case, some distances travelled were too long to be made by bike and not so long to be made by car, but were difficult to be made by public transport.

The main interest for the use of MOIA was for leisure activities and transfers to the airport. The use of the car in these situations could be expensive due to the parking cost, and the public transport or the bike are usually not comfortable to transport luggage, and do not give a safe feeling at nights. Although there is an opportunity for shared ride-hailing to cover these situations, they might require different service characteristics to fulfil the target users of each use case. In particular, we found that both the intention of use and the user requirements depend on the participants' age and frequency of use of the service. In general, the younger the participants and the more they used the service, the greater their usage intention in the proposed use cases and their interest to improve the mentioned service factors. It is worth noting that the main improvements requested by the users were related to the reliability, availability, price and time.

To summarise, the core characteristic of shared ride-hailing that distinguishes itself from traditional DRT is flexibility. Until now, this flexibility is found, mainly, in the way of booking, the route followed, and the determined stops. If other features such as waiting time, walking distance and price could also be adjusted for each use case and target user, considering external factors like weather or strikes, a significant increase in the use of this type of services might be reached.

The limitations of the research were the following:

- Due to the service test having a limited number of vehicles, MOIA test users had to first request the access to the service, and then, wait for the acceptance and download the app. Therefore, test users were people interested in this type of service from the very beginning, and because of that, their statistics of use and their intentions might not be extrapolated to the whole potential customer base. Since MOIA turned into commercial operation in Hanover after the service test, next steps may include conducting a survey to these new customers, and comparing the results obtained with the current analysis.

- The cost of MOIA was much lower than that of other means of transport, which might have led the testers to use the service in some use cases where, by paying a commercial price, they would have not done so, or at least not as frequently. Therefore, to verify the most appropriate use cases for a shared ride-hailing service, users that pay a commercial price for the service should be interviewed.

- Despite the low cost of the rides, the service provided was a test, and consequently, availability was limited and travel times were not always accurate. Therefore, these facts discouraged the use of MOIA for some use cases and influenced the highest rated improvement to be the prebooking. Future work may include validating the level of importance of the improvements presented in this paper in a commercial service.

- The survey was designed to last a maximum of 10 minutes, thus some questions such as to better define the users and their trips could not be included. Next steps should enable to better define the target groups and their mobility patterns with in-depth surveys or face-to-face interviews with a sample of the wider population. Furthermore, questions regarding the intention of use for a range of price points, and questions on reasons for not using the service, should also be included.

- The study was based only in one particular city, Hanover, which as most European cities has a well-established public transport. To validate the most suitable service areas, including the surrounding of the cities, next studies should analyse other types of cities, and also, cities with rudimentary public transport.

In spite of the aforementioned limitations, which are a part of the future research, this research show that there is a big interest on using app-based shared ride-hailing services once citizens have already tried them. Therefore, pilot tests are necessary to both familiarise target users with these services, and to be able to detect market niches and study the user requirements. 


\section{DECLARATION OF CONFLICTING INTERESTS}

The authors declared no potential conflicts of interest with respect to the research, authorship, and/or publication of this article.

\section{ACKNOWLEDGEMENTS}

The authors wish to thank the referees for their insightful comments on an earlier version of the paper. This work was supported by MOIA GmbH, SEAT, S.A., and Generalitat de Catalunya - AGAUR [grant number 2016 DI 023]. 


\section{REFERENCES}

Alonso-Mora, J., Samaranayake, S., Wallar, A., Frazzoli, E., \& Rus, D. (2017). On-demand high-capacity ride-sharing via dynamic trip-vehicle assignment. Proceedings of the National Academy of Sciences, 114(3), 462-467. https://doi.org/10.1073/pnas.1611675114

Basnal, P., Singh, V., Shukla, A., Kumar, D., \& Kadam, A. (2015). Demand Responsive Transport. IJISET - International Journal of Innovative Science, Engineering \& Technology, 2(4).

Bliss, L. (2018, March 8). Transit Agencies and Ride-Hailing Companies Are Having a Dangerous Affair. Retrieved October 7 , 2018, from CityLab website: https://www.citylab.com/transportation/2018/08/where-ride-hailing-and-transit-go-hand-inhand/566651/

Bonazzi, R., \& Pigneur, Y. (2015, January). The Hitchhiker's Guide to the Galaxy of Dynamic Ridesharing. 1207-1216. https://doi.org/10.1109/HICSS.2015.146

Brake, J., \& Nelson, J. D. (2007). A case study of flexible solutions to transport demand in a deregulated environment. Journal of Transport Geography, 15(4), 262-273. https://doi.org/10.1016/j.jtrangeo.2006.08.006

Brake, J., Nelson, J., \& Wright, S. (2004). Demand responsive transport: towards the emergence of a new market segment. Journal of Transport Geography, 12, 323-337. https://doi.org/10.1016/j.jtrangeo.2004.08.011

Chen, L., Mislove, A., \& Wilson, C. (2015). Peeking Beneath the Hood of Uber. 495-508. https://doi.org/10.1145/2815675.2815681

Davison, L., Enoch, M., Ryley, T., Quddus, M., \& Wang, C. (2012). Identifying potential market niches for Demand Responsive Transport. Research in Transportation Business \& Management. https://doi.org/10.1016/j.rtbm.2012.04.007

Elmer, C., Pauly, M., Stotz, P., \& Tack, A. (2018). Verkehr: So pendelt Deutschland zu Arbeit. Retrieved December 9, 2018, from Spiegel online website: http://www.spiegel.de/wirtschaft/verkehr-so-pendelt-deutschland-zu-arbeit-a-1187172.html

Enoch, M., Potter, S., Parkhurst, G., \& Smith, M. (2004). INTERMODE: innovations in Demand Responsive Transport [Final report]. Retrieved from Department for Transport and Greater Manchester Passenger Transport Executive website: http://www.dft.gov.uk

Gao, S., \& Zhang, X. (2016). Understanding Business Models in the Sharing Economy in China: A Case Study. Social Media: The Good, the Bad, and the Ugly, 9844, 661-672. https://doi.org/https://doi.org/10.1007/978-3-319-45234-0_59

Gilibert, M., Ribas, I., \& Rodriguez-Donaire, S. (2017, October 6). Analysis of mobility patterns and intended use of shared mobility services in the Barcelona region. Presented at the European Transport Conference 2017, Barcelona. Retrieved from https://aetransport.org/en-gb/past-etc-papers/conference-papers-2017?state=b\&abstractId=5734

Hall, J., Kendrick, C., \& Nosko, C. (2015). The Effects of Uber's Surge Pricing: A Case Study. The University of Chicago Booth School of Business. Retrieved from http://1g1uem2nc4jy1gzhn943ro0gz50.wpengine.netdna-cdn.com/wpcontent/uploads/2016/01/effects_of_ubers_surge_pricing.pdf

Hall, J. V., \& Krueger, A. B. (2015). An Analysis of the Labor Market for Uber's Driver-Partners in the United States. Princeton University Industrial Relations Section Working Paper, 587. Retrieved from https://assets.documentcloud.org/documents/1507970/uberstudy.pdf

Hosny, M., \& Mumford, C. (2009, July 16). New Solution Construction Heuristics for the Multiple Vehicle Pickup and Delivery Problem with Time Windows. Presented at the MIC 2009: The VIII Metaheuristics International Conference, Hamburg, Germany.

Interreg Europe. (2018, June). Demand-responsive transport: A Policy Brief from the Policy Learning Platform on Low-carbon economy. Retrieved from https://www.interregeurope.eu/fileadmin/user_upload/plp_uploads/policy_briefs/2018-0627_Policy_Brief_Demand_Responsive_Transport.pdf

Jain, S., Ronald, N., Thompson, R., \& Winter, S. (2017). Predicting susceptibility to use demand responsive transport using demographic and trip characteristics of the population. Travel Behaviour and Society, 6, 44-56. https://doi.org/10.1016/j.tbs.2016.06.001

MOIA. (2018). Ridesharing in Hannover | MOIA. Retrieved July 2, 2018, from MOIA Hannover website: https://www.moia.io/deDE/hannover

Morozov, E. (2016, December 15). Silicon Valley, el nuevo centro de poder ¿será la capital de un imperio que gobernará el mundo? Vanguardia Dossier, (63), 21-26.

Nelson, J. D., \& Phonphitakchai, T. (2012). An evaluation of the user characteristics of an open access DRT service. Research in Transportation Economics, 34(1), 54-65. https://doi.org/10.1016/j.retrec.2011.12.008

OECD. (2015, April 1). Urban Mobility System Upgrade. International Transport Forum.

Region Hannover. (2018). Leben in der Region Hannover. Retrieved April 1, 2019, from Das offizielle Portal der Region und der Landeshauptstadt Hannover website: https:/www.hannover.de/Leben-in-der-Region-Hannover

Rimmer, P. J. (1984). THE ROLE OF PARATRANSIT IN SOUTHEAST ASIAN CITIES1. Singapore Journal of Tropical Geography, 5(1), 45-62. https://doi.org/10.1111/j.1467-9493.1984.tb00145.x

Rogers, B. (2015). The social costs of Uber. University of Chicago Law Review Dialogue, Forthcoming. Retrieved from http://papers.ssrn.com/sol3/papers.cfm?abstract_id=2608017 
Ross, H. (2015). Ridesharing's House of Cards: O'connor V. Uber Technologies, Inc. and the Viability of Uber's Labor Model in Washington. Wash. L. Rev., 90, 1431.

Ryley, T. J., Stanley, P. A., Enoch, M. P., Zanni, A. M., \& Quddus, M. A. (2014). Investigating the contribution of Demand Responsive Transport to a sustainable local public transport system. Research in Transportation Economics, 48, 364 372. https://doi.org/10.1016/j.retrec.2014.09.064

Watanabe, C., Naveed, K., \& Neittaanmäki, P. (2016). Co-evolution of three mega-trends nurtures un-captured GDP - Uber's ridesharing revolution. Technology in Society, 46, 164-185. https://doi.org/10.1016/j.techsoc.2016.06.004

Watanabe, C., Naveed, K., Neittaanmäki, P., \& Fox, B. (2017). Consolidated challenge to social demand for resilient platforms Lessons from Uber's global expansion. Technology in Society, 48, 33-53. https://doi.org/10.1016/j.techsoc.2016.10.006

Weckström, C., Mladenović, M. N., Ullah, W., Nelson, J. D., Givoni, M., \& Bussman, S. (2018). User perspectives on emerging mobility services: Ex post analysis of Kutsuplus pilot. Research in Transportation Business \& Management. https://doi.org/10.1016/j.rtbm.2018.06.003

Yu, B., Ma, Y., Xue, M., Tang, B., Wang, B., Yan, J., \& Wei, Y.-M. (2017). Environmental benefits from ridesharing: A case of Beijing. Applied Energy, 191, 141-152. https://doi.org/10.1016/j.apenergy.2017.01.052 